\title{
Pronunciation Acquisition of the Inflectional Morpheme - ed in English by Nicaraguan Spanish Speakers
}

\author{
Angel M. Davila ${ }^{1 *}$ \\ ${ }^{1}$ Southern Illinois University Carbondale, USA \\ ${ }^{*}$ Corresponding author: Angel M. Davila: mangeld79@siu.edu
}

\section{OPEN ACCESS}

Citation: Davila A.M. (2018) Pronunciation Acquisition of the Inflectional Morpheme - ed in English by Nicaraguan Spanish Speakers.Open Science Journal 3(1)

Received: $30^{\text {th }}$ January 2018

Accepted: $9^{\text {th }}$ February 2018

Published: $21^{\text {st }}$ February 2018

\section{Copyright:@ 2018 This is an} open access article under the terms of the Creative Commons Attribution License, which permits unrestricted use, distribution, and reproduction in any medium, provided the original author and source are credited.

Funding: The author(s) received no specific funding for this work

Competing Interests: The author have declared that no competing interests exists.

\section{Abstract:}

This descriptive non-experimental quantitative study investigated if the pronunciation of the -ed morphemeim proves as the English proficiency level develops. A random sampling design was used to recruit research participants. A target sample of 48 Nicaraguan English as a foreign language students were chosen from an accessible population $(N=91)$ to participate in this research. The participants' age ranged from 18 to 24 , with a mean age of 21 years. They belonged to three English proficiency levels: high beginners, intermediate, and high intermediate. Findings showed that more advanced English as a Foreign Language learners had a significantly higher pronunciation accuracy on the production of the allomorphs, /t/ and $/ \mathrm{d} /$. Their error rate on these two allomorphs was as low as $9 \%$ and $8 \%$, respectively. Concerning the / $\mathrm{d}$, Id/ allomorph, no significant differences were found among proficiency levels. These results were interpreted in view of the Markedness Differential Hypothesis (Eckman, 1977) and the Similarity Differential Rate Hypothesis (Major \& Kim, 1996). The trends in the data definitely suggested support for the Similarity Differential Rate Hypothesis which postulates that markedness by itself cannot explain the development of L2 learners as they improve their L2 proficiency level. This study offers implications for the teaching of the three phonological realizations of the -ed past tense inflection. 
Keywords: -ed pronunciation, -ed acquisition, -ed morpheme, English past tense of regular verbs

\section{Introduction}

Developing intelligible pronunciation is an objective that learners of English as a foreign language try to achieve. Intelligibility allows English learners not only to be understood but also to comprehend what they hear when communicating (Akram, 2010; Becker \& Kluge, 2014; Jin \& Liu, 2014; Nation \& Newton, 2009; Richards, 2008; Smith, 2011). In addition, Akram (2010) argued that acquiring an intelligible English pronunciation prevents a possible breakdown in communication. According to Jenkins (2004), Nation and Newton (2009), and Becker and Kluge (2014), intelligibility is a central element in making communication successful either with native speakers of the target language or other L2 speakers.

In this respect, one of the linguistic difficulties that Spanish speakers face when learning English as a foreign language is the acquisition of the accurate pronunciation of the three phonological realizations of the inflectional morpheme that marks the past tense of regular verbs in English. It is undeniable that developing a proficient level of the pronunciation of the -edinflectional morpheme would guarantee Spanish speakers a more fluent and intelligible process when communicating past situations or events in English. Androutsopoulou, EspañolEchevarría, and Prévost (2010) observed that second language learners might have some problems when acquiring inflectional morphology and errors such as omission or substitution of the inflectional morpheme in question can happen even at the highest level of proficiency. For instance, wrong production of the inflectional morpheme -ed can be explained by the absence oftense inflections in the L1 system, but also may indicate that the knowledge of inflectional morphology in the learners' L2 is not complete (Androutsopoulou et al., 2010).

Eckman, Elreyes, and Iverson (2003) argued that the process of a second language acquisition is systematic. Second language learners, first, need to acquire the L2 system of phonemes and morphemes, and once these phonological and morphological systems are acquired, they start performing them orally. This means that it can be expected that EFL Spanish speakers will improve their oral production of the three allomorphs of the -ed morpheme as their English proficiency improves.

On the other hand, Eckman et al. (2003) concluded that second language learners can experience learning difficulties during their acquisition of the phonological and syntactic systems of the target language, mainly in those linguistic elements that are different from the native language. Following Eckman et al., it can be predicted that Spanish learners of English as a foreign language are likely to have some difficulties with complex consonant clusters in word final position due to the absence of such clusters in Spanish. This hypothesis is also supported by Yassin (2008) who observed that for adult EFL learners to acquire accurate pronunciation it means learning to pronounce new sounds that do not exist in the phonemic inventory of their L1 or which are not allowed by the phonotactic constraints of their first language. Furthermore, Yassin (2008) also 
observed that one of the difficulties ESL and EFL learners find when learning English is the accurate production of voiceless and voiced consonants in all their phonological variations. It has also been reported that English inflectional morphemes which occur in word final position present pronunciation difficulties to EFL learners (Schwartz, 1993). In view of Schwartz's conclusion, it can be predicted that the -edinflectional morpheme will be a problem for many EFL learners, including Spanish EFL learners.

However, it is important to recognize that the process of second language acquisition depends on various factors such as age and time of exposure to the target language (Birdsong, 1999; Johnson \& Newport, 1989; Long, 1990; Reichle, 2010), learners' motivation, anxiety, language learning aptitude, personality (Ghapanchi, Khajavy \& Asadpour, 2011; Ożańska-Ponikwia, \& Dewaele, 2012; Wesely, 2012), classroom instruction, learning environment, socio-economic conditions, interaction (Dörnyei, 2009) and the phonotactic constraints of their L1 and L2 (Altenberg, 2005; Sebastián-Gallés \& Bosch, 2002; Storkel, Maekawa, $\&$ Hoover, 2010). Since it is difficult to examine all variables in one study, this research focuses on the last factor, the phonotactic difficulties that EFL Spanish speakers (L1) find when producing the three phonological variations of the English past tense - ed morpheme through the act of reading isolated regular English past tense verbs (L2). This study examines as well whether the accurate pronunciation of the three realizations of the -ed morpheme improves with the level of English proficiency. These issues are investigated from the perspective that Spanish disallows complex clusters in word-final positions.

Consequently, this study takes as literature support some postulations regarding L2 phonological acquisition, such as the Markedness Differential Hypothesis, the Similarity Differential Rate Hypothesis, and the phonotactic constraints between English and Spanish, mainly those in word-final position.

\section{Theoretical Framework of the Study}

\section{The Markedness Differential Hypothesis (MDH)}

Eckman (1977) proposed the Markedness Differential Hypothesis based on a phonological theory of markedness. He claimed that language learners' ability to acquire a second language can be calculated based on the comparison of the L1 and L2 syntactic systems and the markedness relations present in Universal Grammar. The essential prediction of the $\mathrm{MDH}$ is that those phonological areas of the L2 which are different from the L1 and are more marked (less frequent sounds) will be difficult for the second language learner. However, according to the MDH, those phonological areas of the L2 which are different from the L1, but are less marked (more frequent sounds)will be easier for L2 learners to acquire.

In a later work (2008), Eckman found that voiceless obstruents, oral vowels and open syllables are unmarked. On the other hand, voiced obstruents, nasalized vowels and closed syllables are considered marked. Helman (2004) agrees with Eckman that EFL learners will face some difficulties in those phonological areas in which English and Spanish are dissimilar. 
Markedness was also discussed by Greenberg (1978) who shared Eckman's (1977) views that phonological areas that are more marked or less common across languages are more difficult to acquire. For example, clusters in word-final position are less common than clusters in initial position across languages, so they can be predicted to present linguistic difficulties for L2 learners. In the context of the present study, out of the three allomorphs of the past tense inflection $-e d$, /t/ and / d/ would be considered more marked for Spanish-speaking learners because these two allomorphs form consonant clusters with the preceding consonants and Spanish disallows complex clusters in word-final position. In fact, Spanish allows only five single coronal consonants sounds [n], [r], [l], [ð], and [s] at the end of words (Lleó, 2003). Consequently, due to markedness, /t/ and /d/ as in '[læft] laughed' and '[bi'la:yd] belonged' will be troublesome for Spanish L2 English learners to acquire.

On the other hand, the allomorph /əd, Id/ as in '[sə'dzestəd, -Id] suggested' would be less marked for EFL Spanish speakers because they form a syllable which is similar to the phonotactics of Spanish final syllables. Specifically, Spanish allows open syllables in final word position as in the word '[be'be] bebé meaning baby' or syllables ending on -VC as in '['arbol] árbol meaning tree' (Lleó, 2003). Therefore, it can be predicted that Spanish EFL learners will encounter fewer problems.

Another supporter of Eckman's (1977) MDH, Carlisle (1998) has also recognized that syntactic and phonological differences between two languages do not always represent difficulties for second language learners. In fact, second language learners are expected to face learning impairments in those areas where the L2 is not only different from the L1, but is also more marked. Consequently, L2 learners are likely to experience fewer difficulties with linguistic elements that are different between two languages but are unmarked.

Hyltenstam (1987) introduced a revised version of the Markedness Deferential Hypothesis proposed by Eckman in 1977, according to which second language learners will not have difficulties with those linguistic elements which are unmarked both in the target language and the native language. However, acquisition will be more difficult with linguistic elements which are marked in the L2 and unmarked in the L1. In addition, it is possible that an unmarked linguistic structure may occur in second language learners' interlanguage in those areas where the native language and the target language share a marked linguistic element.

However, Major and Kim (1996) argued that acquisition difficulties can be measured from another point of view than just learner mistakes. Specifically, they proposed the Similarity Differential Rate Hypothesis to account for these more complex acquisitional difficulties.

\section{The Similarity Differential Rate Hypothesis (SDRH)}

Major and Kim (1996) proposed the Similarity Differential Rate Hypothesis which examines three elements: similarity, dissimilarity and markedness as they relate to the acquisition of a second language. The SDRH claims that linguistic elements that are dissimilar between the L1 and L2 are acquired at faster rates than similar linguistic elements. Consequently, it can be expected for two things 
to happen concerning the acquisition of the past tense inflectional morpheme in English -ed. First, Spanish does not allow complex clusters at the end of words as English does. It permits only five singleton coronal consonants in word-final position[s], [n], [r], [l], and [ð] (Nathan, 2008). Also, the Spanish voiced dental stop /d/ changes to voiced dental fricative [ð] when it occurs in syllable codas (Goldstein, 2001). In view of these three characteristics, the three phonological variations of the affixal morpheme $-e d$ are nonexistent linguistic elements in Spanish. Therefore, following SDRH, it can be predicted that EFL Spanish speakers should not find any major difficulty acquiring and producing the three phonological versions of the inflectional morpheme $-e d$.

Second, the phonemes $/ \mathrm{t} /$ and / d/ which can be found as two allomorphs of the past tense inflection -ed share some similarities such as manner of articulation (plosives) and place of articulation (coronals) in both English and Spanish. They differ slightly in one distinctive feature. Specifically, in Spanish /t/ and /d/ are dentals, whereas in English /t/ and /d/ are alveolars (Gildersleeve-Neumann, Kester, Davis, \& Peña, 2008). Thus, these sounds can be expected to be problematic for EFL Spanish learners, first because these sounds share some similarities in both languages and second because they are more marked for this environment in Spanish than in English because they do not occur in word-final position in Spanish. Major and Kim (1996) recognized that even when markedness is not explicit in their hypothesis, it is a very important aspect to consider since the degree of markedness can increase or decrease the rate of acquisition of certain aspects of the target language.

In fact, Major and Kim (1996) formulated the SDRH as three distinctive hypotheses:

Hypothesis 1: Linguistic elements that are different between the L1 and L2 are easier to acquire than linguistic aspects that are similar in both languages. This is considered the most general form of the SDRH hypothesis.

Hypothesis 2: Advanced L2 learners will demonstrate higher level of performance when acquiring dissimilar linguistic elements than when acquiring linguistic elements that share some similarities between the L1 and L2. On the other hand, L2 beginning learners are expected to show higher competence with alike linguistic elements present in the L1 and L2 than with dissimilar linguistic elements. The explanation why beginning learners perform better with alike linguistic elements is based on transfer. Specifically, they substitute the L2 linguistic elements with their closest equivalents in the L1. Regarding pronunciation, second language beginning learners tend to replace novel L2 sounds with their closest L1 phonological equivalents which can be very different acoustically and perceptually. On the other hand, L2 advanced learners gain an awareness of these phonological differences which leads to a more accurate pronunciation.

Hypothesis 3: An L2 sound that is different from an L1 sound is acquired faster than an L2 sound that is similar to an L1 sound. This postulation of the $\mathrm{SDRH}$ is similar to the second hypothesis except that it does not make any claim concerning the final level of proficiency that a L2 learner might get. It only hypothesizes that L2 learners acquire unlike linguistic elements to a higher rate than the alike phonological elements. 


\section{Past tense inflectional morphology in English and Spanish}

The English regular past tense is formed by adding the inflectional morpheme $-e d$ to the bare infinitive verb form in all grammatical persons, singular and plural (Salaberry, 2000). Thus, the -edinflection is a bound morpheme which carries the grammatical meaning of past tense. Although the morphology of the English regular past tense is simple, what complicates the acquisition of the morpheme ed is the fact that it has three allomorphs: (1) / t/ as in worked, (2) /d/ as in listenedand eyed, and (3) / od or $\mathrm{Id} /$ as in wanted. These three phonological realizations of the

- edinflectional morpheme are determined by phonological rules. Specifically, the voiceless alveolar sound / $\mathrm{t} /$ follows voiceless non-alveolar stop consonants such as $/ \mathrm{k} /$ and $/ \mathrm{p} /$ as in asked and helped; whereas the voiced alveolar sound /d/ is realized after voiced non-alveolar stop consonants, such as /g/ and /b/ as in dragged and described and vowels. The /od or $\mathrm{Id} /$ form is used when the verb ends with an alveolar stop / $\mathrm{t} /$ or $/ \mathrm{d} /$ sound as in visited and needed (Dalal \& Loeb, 2005).

Spanish, on the other hand, is a highly inflected language when it comes to the past tense of regular verbs. Bowden, Gelfand, Sanz, and Ullman (2010) observed that Spanish shows three infinitives categories of verbs: -ar verbs, - er verbs, and -ir verbs. It means that regular verbs can fall in any of these three groups, for instance, hablar (to speak), comer (to eat) and vivir (to live). Moreover, Spanish has two types of past tense namely past preterit and past imperfect which take the inflections summarized in Table 1, as based on Bowden et al. (2010) and Salaberry (2000).

Table 1: Inflections for regular past verbs in Spanish

\begin{tabular}{ccccccc}
\hline \multicolumn{3}{c}{ Past Preterit } & & \multicolumn{3}{c}{ Past Imperfect } \\
Inflections added to the stem & & \multicolumn{2}{c}{ Inflections added to the stem } \\
\hline & -ar & -er & -ir & -ar & -er & -ir \\
\hline 1st Person Singular & - é & $-i ́$ & $-i$ & -aba & -ía & -ía \\
2nd Person Singular & -aste & -iste & -iste & -abas & -ías & -ías \\
3rd Person Singular & -ó & -ió & -ió & -aba & -ía & -ía \\
1st Person Plural & -amos & -imos & -imos & -abamos & -íamos & -íamos \\
2nd Person Plural & -asteis & -isteis & -isteis & -abais & -íais & -íais \\
3rd Person Plural & -aron & ieron & ieron & -aban & -ían & -ían \\
\hline
\end{tabular}

In terms of inflectional morphology, we see that Spanish is more inflected than English. This fact may make us think that Spanish speakers learning English as a foreign language would not face major linguistic problems in acquiring the -edaffixal morpheme of the English regular past tense. However, Table 1 reveals a shared characteristic of the Spanish past tense inflections, particularly, it is not difficult to notice that past tense inflections in Spanish end in an open syllable or in coronal consonants such as $/ \mathrm{n} /$ or $/ \mathrm{s} /$ depending on the grammatical person. When this characteristic of Spanish is juxtaposed with the 
three allomorphs of the English - edinflection, the possibility of a Spanish learner of English having production problems with the -edinflectional morpheme becomes predictable.

This predicted problem is further substantiated by the different types of orthographies that English and Spanish have. Although both languages belong to the group of alphabetical orthographies, they are also dissimilar. According to Carlisle (2000), English is a language of deep orthography, whereas Spanish is a language of shallow orthography. As a language of deep orthography, English does not have a direct correspondence between graphemes and phonemes (Commissaire, Duncan, \& Casalis, 2011; Carlisle, 2000). In Spanish, such direct correspondence exists and decoding graphemes into phonemes is rather straightforward (Baker, 2011). This difference between the orthographies of English and Spanish can further affect Spanish English learners' decoding practices as they are likely to transfer their L1 skills into their L2 performance (Ramirez, Chen, Geva, \& Kiefer, 2010).

\section{Word-final Position Phonotactic Constraints in Spanish and English}

Since the purpose of this study is to examine the phonological realizations of the past tense inflection -edin the interlanguage of Spanish learners of English, it is also important to consider the phonotactic constraints in word-final position both in Spanish and in English. Pertaining to this matter, Storkel, Maekawa and Hoover (2010) defined phonotactics as the number of allowed arrangements of speech sounds that constitute the phonological knowledge of a native speaker of any language. Consequently, native speakers of any language may easily recognize that certain phonological elements from other languages violate the phonotactic constraints of their language. They may also identify that their language shares some segment sequences with other languages (Altenberg, 2005). Altenberg also observed that second language acquisition is influenced by the phonotactic constraints of the L1 and the L2. For instance, if the L1 disallows consonant clusters at the end of words and the target language (L2) allows them, this phonological difference may influence the acquisition of these particular linguistic elements. In this light, Sebastián-Gallés and Bosch (2002) recommend that in building learners' receptive vocabulary, language-specific phonotactic constraints can be introduced through auditory speech input in order to facilitate their acquisition.

As for syllable structure, Harris (1983) found that syllable structure of a language keeps a close interaction with other linguistic elements such as the phonotactics of that language. In other words, phonotactic constraints of a language take syllable structure as the unit of linguistic organization of that language. That is, syllable structure determines how the phonemes of a particular language are sequentially distributed (Harris, 1983).

Yavas and Core (2001) argue that English and Spanish show some major differences in their use of word-final consonants. English allows stops, fricatives, nasals, and liquid consonant sounds at the end of words (Yavas \& Core, 2001), 
whereas Spanish accepts only singleton coronal sounds, [n], [r], [l], [ð], and [s], word-finally (Davidson, 2011; Goldstein, 2001; Nathan, 2008).

Pursuing this further, Abushihab (2010) observed that English syllable structure may contain up to four consonants in word-final position, -V (CCCC). Moreover, it was observed that English may permit word-final position combinations such as -VC, -VCC, -VCCC, and -VCCCC (Hansen, 2004; Nathan, 2008; Shepherd, 2003; Yavas \& Core, 2001). On the other hand, Spanish allows only -VC word endings wherein the last element is optional (Harris, 1983).

In view of the acquisition of word-final position, Lee (1987) in a study with first grade Spanish speakers found that -VC word endings were difficult to acquire because of the limited number and type of consonants allowed at the end of words in Spanish. Rauber and Baptista (2004) agreed with Lee's finding by adding that English permits consonant sounds at the end of words in a wider range of places and manners of articulation compared to Spanish which allows coronals only. Helman (2004), for instance, affirmed that learners acquiring English might find some difficulties in the following word-final phonological environments: [-rd], [-st], [-ng],

[-sk], [-z], [-t], and [-mp] because Spanish prohibits these realizations at the end of words.

In summary, English word-final consonant sounds tend to be difficult in the beginning stages for Spanish speakers acquiring English, mainly because complex word-endings are disallowed in Spanish (Yavas \& Core, 2001). In this light, it can be predicted that the affix -ed will present a certain level of difficulty to Spanish speakers because it occurs mostly in word-final complex clusters. This is because Spanish allows fewer word-final consonants than English, which explains why the acquisition of English word-final clusters may be difficult for Spanish speakers (Demuth, Culbertson, \& Alter, 2006). Thus, in the process of acquiring English word-final clusters, native Speakers of Spanish might employ some repair processes to acquire word-final complex consonant combinations, such as compensatory vowel lengthening, deletion of clusters, or vowel epenthesis. Spanish speakers learning English as a foreign language may master the pronunciation of the three phonological realizations of the -ed morpheme as they increase their phonological and morphological awareness of English ( $\mathrm{Hu}, 2010$; Ramirez, et al., 2010; Wang, Park, \& Lee, 2006).

In short, the purpose of this study was to investigate whether or not the pronunciation of the -ed morpheme, which marks the past tense of regular verbs in English, improved as students increase their level of English proficiency. It was found that Spanish speakers in lower levels of English proficiency tend to transfer phonological characteristics to the target language, in this case, English, and that later in their learning process they focus more on the acquisition of the target sounds. This was the case of more advanced EFL learners in this study. That is to say, their level of accuracy on two, $/ \mathrm{t} /$ and $/ \mathrm{d} /$, of the phonological realizations of the $-e d$ morpheme was higher compared to beginning levels. 


\section{Materials and methods}

This descriptive non-experimental quantitative study investigated two research questions: Does the pronunciation of the three phonological variations of the English past tense inflectional morpheme -ed improve with the level of English proficiency of EFL Spanish speakers? and Which of the three phonological realizations of the English past tense inflectional morpheme $-e d$ is the most mispronounced? These research questions were examined in view of the theories MDH (Eckman, 1977) and SDRH (Major \& Kim, 1996). A random sampling design was used to select research participants. Out of the accessible population $(N=91)$, a target sample of 48 Nicaraguan English as a foreign language learners were selected to participate in this research. The participants' age ranged from 18 to 24, with a mean age of 21 years. The 48 research participants were learning English as a foreign language in an intensive English program at a Nicaraguan university and belonged to three English proficiency levels: high beginners, intermediate, and high intermediate. To select the 48 participants, all the names of each proficiency group were put in a box and then were take one by one. Although gender was not a variable of interest, an equal number of male and female participants was randomly selected for each proficiency group. That is, every individual had an equal probability of being included in the sample. The first eight randomly selected female names and the first eight randomly selected male names formed the sample for each of the three proficiency levels. The instrument for data collection was composed of 44 isolated regular past tense verbs to measure the three phonological realizations of the -ed inflectional morpheme, 4 for / $\mathrm{d}$, Id/, 12 for $/ \mathrm{t} /$ and 28 for $/ \mathrm{d} /$. Participants were asked to read aloud the 44 words three times. Two raters, the researcher and an experienced native English speaker teacher, rated the recorded pronunciation of each participant. A third rater, an expert in phonology and phonetics, was called in case the first two raters had different scores when rating the pronunciations of the words in the research instruments. The researcher carried out two different types of procedures to validate the instruments, namely, expert validation (with a doctor in phonetics and phonology, with more than 15 years in teaching and research in those areas) and pilot-testing, with a similar sample. As for data analysis, three one way analyses of variance (ANOVAs) were used to compare differences in the read-aloud production of the -ed morpheme utilizing the statistical software SPSS (PAWS 20). In addition, frequency tables were used to illustrate the patterns of mispronunciations of -ed within and between proficiency levels. Error patterns were identified and interpreted in relation to the theories of transfer and markedness.

\section{Results}

The analysis included 3 one-way ANOVAs for each of the three allomorphs at level of significance alpha $=.05$. In addition, frequencies of errors were calculated and displayed within and between levels of proficiencies. The results are presented into three sections, one for each allomorph. 
The first ANOVA examined the effect of the three proficiency levels on the production of the allomorph / əd/ or / Id/ as the mean scores did not make a distinction between whether -edwas pronounced as /od/ or / Id/. Table 2 summarizes the descriptive statistics for the 3 proficiency level groups on their production of the allomorph /od or Id/.

Table 2: Descriptive statistics for proficiency level and errors in the production of /əd, $\mathrm{Id} /$

\begin{tabular}{lcccccccc}
\hline Proficiency level & $\mathrm{N}$ & Mean & SD & \% Wrong & \multicolumn{2}{c}{$95 \%$ CI } & Min & Max \\
& & errors & & & Lower & Upper & & \\
\hline High beginners & 16 & .20 & .21 & $20 \%$ & .09 & .31 & .00 & .50 \\
Intermediate & 16 & .28 & .22 & $28 \%$ & .16 & .40 & .00 & .50 \\
High & 16 & .23 & .23 & $23 \%$ & .11 & .36 & .00 & .75 \\
intermediate & & & & & & & & \\
\hline
\end{tabular}

Examining the distribution of scores within each proficiency level group, it was found that all three distributions met the assumption of normality. The descriptive statistics did not show any outliers. Prior to conducting the one-way ANOVA, Levene's test was performed so as to make sure for violations of the assumption of homogeneous variances. The findings demonstrated that this assumption was observed, $F(2,45)=9.18, p=.918$, and ANOVA results could be interpreted without concern for their validity. The one-way ANOVA results showed that the three proficiency level groups (high beginners, intermediate, and high intermediate) were not significantly different from each other, $F(2,45)=$. $507, p=.606$, partial Eta squared $=.022$. This pattern is best seen in the descriptive statistic results which show that the three proficiency level groups had almost the same rate of errors, respectively $20 \%, 28 \%$, and $23 \%$, as the lowest percentage was among the lowest proficiency group. Since the ANOVA results were not significant, Tukey post hoc tests were not performed for this particular realization of the -edmorpheme.

Further, the analysis included a more detailed examination of the errors per word in an attempt to find whether the error rate varies per word and thus to identify words that may be causing more problems than others. Table 3 summarizes the percentage of errors per word within each level.

Table 3: Error frequency of /əd, Id/ per word within level of proficiency

\begin{tabular}{lccc}
\hline Words & $\begin{array}{c}\text { High beginners } \\
\% \text { Wrong }\end{array}$ & $\begin{array}{c}\text { Intermediate } \\
\% \text { Wrong }\end{array}$ & $\begin{array}{c}\text { High intermediate } \\
\% \text { Wrong }\end{array}$ \\
\hline Visited & $6 \%$ & $6 \%$ & $0 \%$ \\
Wanted & $6 \%$ & $0 \%$ & $6 \%$ \\
Included & $25 \%$ & $56 \%$ & $50 \%$ \\
Decided & $44 \%$ & $50 \%$ & $38 \%$ \\
\hline
\end{tabular}

As seen in Table 3, the words with the least number of errors were visited and wanted, and the words with the highest instances of errors were included and decided. However, these errors were not consistent among proficiency levels. In the case of the word visited, the lowest wrong percentage was shown by the high intermediate level, $0 \%$. The other two proficiency levels showed $6 \%$ of errors 
each. Concerning wanted, the intermediate level outperformed the other two English proficiency levels with $0 \%$ against $6 \%$ wrong. On the other hand, included and decided were the tokens with the highest number of errors. Interestingly, the intermediate and high intermediate level had a higher percentage of errors when reading the word included, $56 \%$ and $50 \%$ respectively, than the high beginning group. Lastly, $100 \%$ of the errors in the production of /əd or Id/ involved the omission of the-edinflection during the read-aloud task.

The second ANOVA investigated the effect of the three levels of proficiency on the performance of the phonological realization $/ t /$ of the -edaffixal morpheme. Table 4 shows the descriptive statistics for the three proficiency level groups when performing the allomorph $/ \mathrm{t} /$.

Table 4: Descriptive statistics for proficiency level and errors in the production of / $t /$

\begin{tabular}{llllccccc}
\hline Proficiency level & $\mathrm{N}$ & Mean & $\mathrm{SD}$ & \% Wrong & \multicolumn{2}{c}{$95 \%$ CI } & Min & Max \\
& & errors & & & Lower & Upper & & \\
\hline High beginners & 16 & .87 & .16 & $87 \%$ & .76 & .99 & .58 & 1.00 \\
Intermediate & 16 & .42 & .34 & $42 \%$ & .30 & .53 & .00 & 1.00 \\
High & 16 & .09 & .14 & $9 \%$ & -.02 & .21 & .00 & .50 \\
intermediate & & & & & & & & \\
\hline
\end{tabular}

Analyzing the distribution of scores within each level of English proficiency, it was found that all three distributions met the assumption of normality. Since Levene's test showed a violation of the homogeneity assumption with $p<.001$, Fmax was calculated and compared to the predicted Fmax following Kirk (1995). Accordingly, the homogeneity of variances assumption was assumed with Fmax calculated $=5.49$ being smaller than Fmax predicted $=5.5$ at alpha $=.01$. The one-way ANOVA revealed that the independent variable proficiency level had a significant effect on participants' skill to perform the phonological realization / $\mathrm{t} /$ of the English affixal morpheme $-e d, F(2,45)=46.385, p=.001$, partial Eta squared $=.673$. Specifically, this significant effect is evident in the descriptive statistics which show that the mean scores of errors decreased as the proficiency level went up.

Since the analysis consisted of three proficiency level groups, a Tukey multiple comparison post hoc test was performed in order to investigate which proficiency level groups were significantly different from each other. This would indicate at what proficiency level the increase in performing the allomorph $/ \mathrm{t} /$ of the edmorpheme is more evident and how the ability to produce the phonological realization /t/ grows as proficiency level improves. Tukey's results showed that all groups were significantly different from each other $(p<.001$ for all comparisons) as the error rate decreased from $87 \%$ (high beginners) to $9 \%$ (high intermediate).

The relationship between errors in pronunciation and proficiency level is best illustrated by Figure 1 which shows a proficiency-related decline in the number or errors in the production of the allomorph / $\mathrm{t} /$ of the English -edaffixal morpheme. 


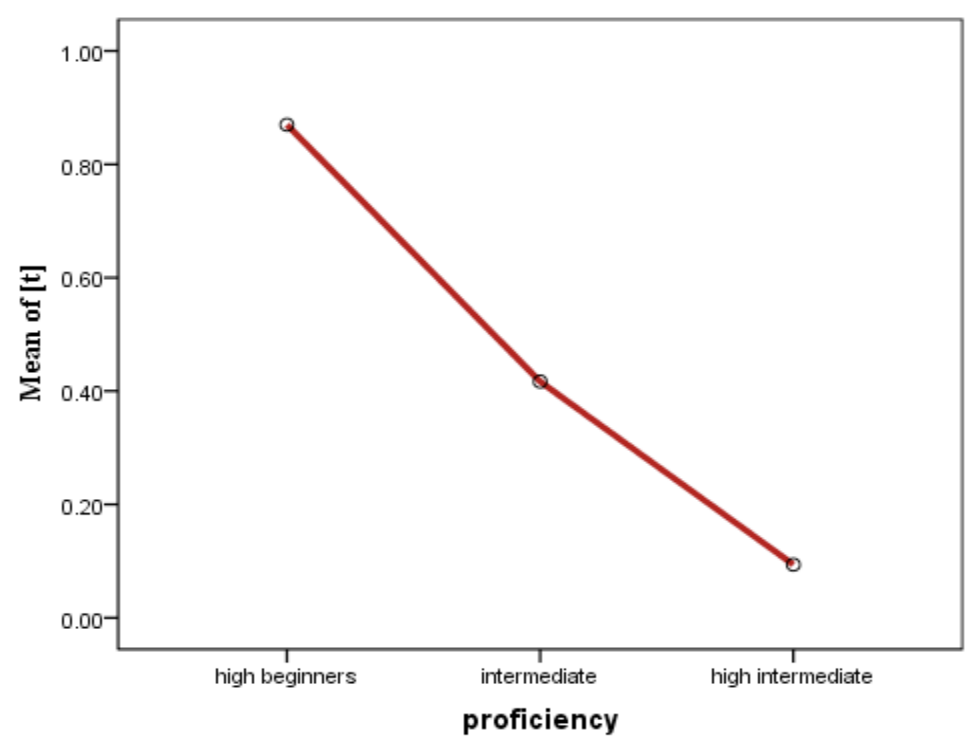

Figure 1. Plot of proficiency level group mean scores on the phonological performance of $/ \mathrm{t} /$

The statistical analysis was followed by a more detailed analysis of the errors per word with the purpose of finding if the error rate varies per word and thus to identify words that may be causing more problems than others. Table 5 summarizes the percentage of errors per word within each level

Table 5: Error frequency of / $/$ per word within level of proficiency

\begin{tabular}{lccc}
\hline Words & $\begin{array}{c}\text { High beginners } \\
\% \text { Wrong }\end{array}$ & $\begin{array}{c}\text { Intermediate } \\
\% \text { Wrong }\end{array}$ & $\begin{array}{c}\text { High intermediate } \\
\% \text { Wrong }\end{array}$ \\
\hline Helped & $63 \%$ & $19 \%$ & $0 \%$ \\
Pushed & $75 \%$ & $38 \%$ & $6 \%$ \\
Stopped & $81 \%$ & $19 \%$ & $0 \%$ \\
Stuffed & $81 \%$ & $38 \%$ & $6 \%$ \\
Practiced & $81 \%$ & $38 \%$ & $13 \%$ \\
Wished & $88 \%$ & $31 \%$ & $19 \%$ \\
Passed & $94 \%$ & $31 \%$ & $6 \%$ \\
Looked & $94 \%$ & $44 \%$ & $6 \%$ \\
Asked & $94 \%$ & $50 \%$ & $19 \%$ \\
Attached & $94 \%$ & $56 \%$ & $0 \%$ \\
Approached & $100 \%$ & $31 \%$ & $19 \%$ \\
Laughed & $100 \%$ & $69 \%$ & $19 \%$ \\
\hline
\end{tabular}

Table 5 shows that, concerning the production of the allomorph $/ \mathrm{t} /$, the distribution of errors per word was related to proficiency level. The beginning level participants had higher frequencies of errors in the production of all tokens 
and the high intermediate level had the lowest percentages of errors per word. The word that was the most problematic across proficiency levels the word laughed, with $100 \%$ wrong productions by the high beginners, $69 \%$ by the intermediate proficiency level, and $19 \%$ by the high intermediate level of English proficiency. Other words with similar distributions of errors were the words asked and approached. In most of these wrong productions, participants pronounced the $-e d$ inflection as / $\partial \mathrm{d}$ or $\mathrm{Id} /$ instead of / $\mathrm{t} /$. In other words, they were syllabifying the $-e d$ in words like achieved, asked, stopped. There also were some cases of deletion, or not pronouncing -edat all.

The last ANOVA investigated the effect of the three proficiency levels on the read-aloud production of the allomorph /d/ of the $-e d$ affixal morpheme. Table 6 shows the descriptive statistics for the three proficiency level groups when reading aloud the allomorph /d/.

Table 6: Descriptive statistics for proficiency level and errors in the production of /d/

\begin{tabular}{lcccccccc}
\hline Proficiency level & $\mathrm{N}$ & Mean & $\mathrm{SD}$ & \% Wrong & \multicolumn{2}{c}{$95 \%$ CI } & Min & Max \\
& & errors & & & Lower & Upper & & \\
\hline High beginners & 16 & .69 & .18 & $69 \%$ & .60 & .79 & .32 & .93 \\
Intermediate & 16 & .28 & .19 & $28 \%$ & .18 & .38 & .00 & .61 \\
High & 16 & .08 & .09 & $8 \%$ & .03 & .12 & .00 & .29 \\
intermediate & & & & & & & & \\
\hline
\end{tabular}

Examining the distribution of scores within each level of English proficiency, it was noted that all three distributions met the assumption of normality. Prior to conducting the one-way ANOVA, Levene's test was carried out in order to examine for violations of the assumption of homogeneous variances. The results showed that this assumption was observed, $F(2,45)=0.57, p=.057$. The oneway ANOVA demonstrated that the independent variable proficiency level had a significant effect on participants' ability to produce the allomorph $/ \mathrm{d} /$ of the English past morpheme $-e d, F(2,45)=62.714, p=.001$, partial Eta squared $=$ .736. With regard to the descriptive statistics (Table 5), the ANOVA results suggest that as the proficiency level improves, the errors in the production of $-e d$ as /d/ decrease significantly. To find out whether this increase was significant at each level of proficiency, a Tukey post hoc test was performed. The results showed that all comparisons were significant $(p<.001)$.

In other words, the decrease in errors from $69 \%$ (high beginners) to $8 \%$ (high intermediate) was systematic and could be attribute to a developmental trend in the production of $-e d$ as $/ \mathrm{d} /$. Figure 2 illustrates the decline of errors with level of proficiency. 


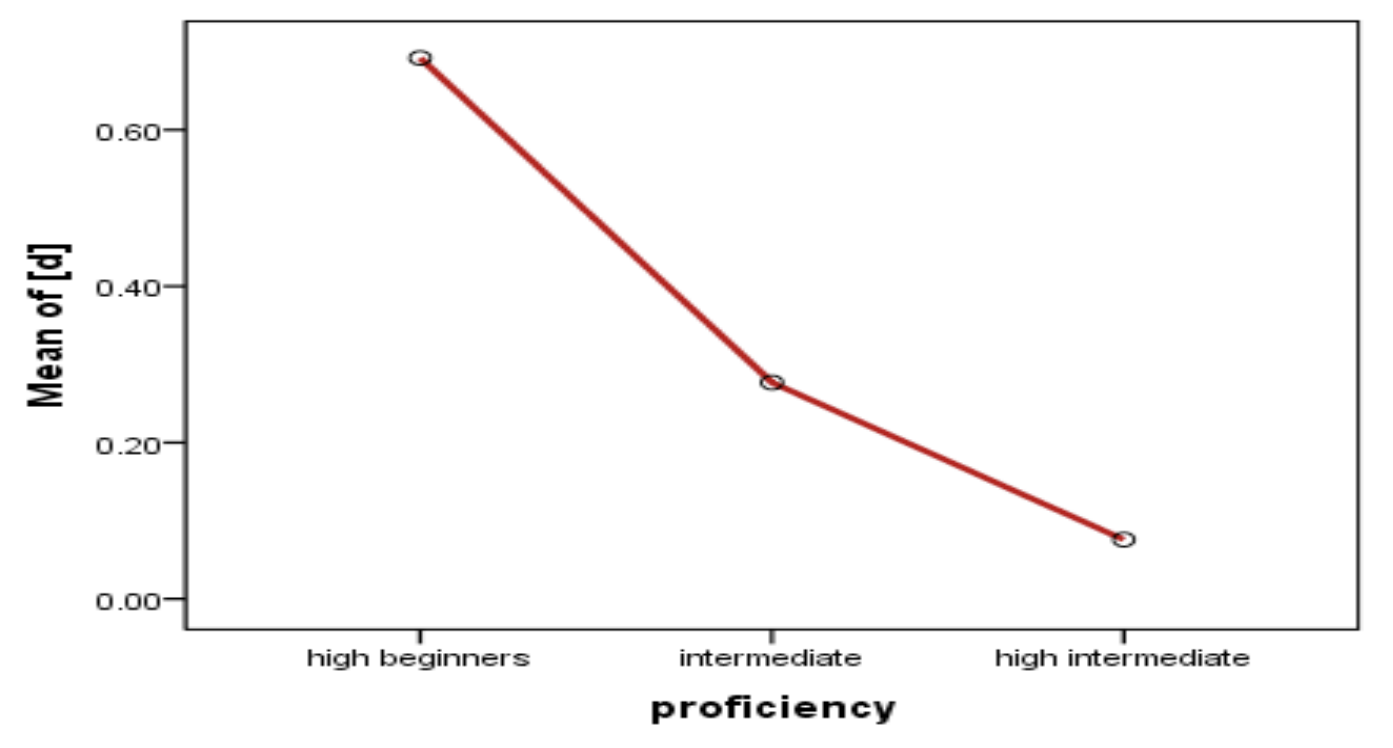

Figure 2. Plot of proficiency level group mean scores on the phonological production of $/ \mathrm{d} /$

Furthermore, the analysis covered a more detailed examination of the errors per word with the objective of learning whether the error rate changes per word and thus to learn which words may be causing more pronunciation difficulty than others. Table 10 shows the percentage of errors per word within each level.

Table 7: Error frequency of /d/ per word within level of proficiency

\begin{tabular}{lccc}
\hline Words & $\begin{array}{c}\text { High beginners } \\
\% \text { Wrong }\end{array}$ & $\begin{array}{c}\text { Intermediate } \\
\% \text { Wrong }\end{array}$ & $\begin{array}{c}\text { High intermediate } \\
\text { Wrong }\end{array}$ \\
\hline Agreed & $6 \%$ & $6 \%$ & $0 \%$ \\
Disagreed & $6 \%$ & $6 \%$ & $0 \%$ \\
Loved & $25 \%$ & $19 \%$ & $0 \%$ \\
Glued & $31 \%$ & $0 \%$ & $0 \%$ \\
Clued & $31 \%$ & $6 \%$ & $0 \%$ \\
Obeyed & $31 \%$ & $19 \%$ & $13 \%$ \\
Played & $38 \%$ & $19 \%$ & $0 \%$ \\
Flowered & $56 \%$ & $13 \%$ & $6 \%$ \\
Lived & $63 \%$ & $13 \%$ & $0 \%$ \\
Ordered & $63 \%$ & $25 \%$ & $19 \%$ \\
Named & $63 \%$ & $19 \%$ & $0 \%$ \\
Remained & $69 \%$ & $25 \%$ & $13 \%$ \\
Dreamed & $69 \%$ & $31 \%$ & $19 \%$ \\
Called & $69 \%$ & $31 \%$ & $6 \%$ \\
Learned & $75 \%$ & $25 \%$ & $6 \%$ \\
Belonged & $75 \%$ & $50 \%$ & $13 \%$ \\
Described & $88 \%$ & $25 \%$ & $6 \%$ \\
Recognized & $88 \%$ & $25 \%$ & $0 \%$ \\
\end{tabular}




\begin{tabular}{lccc} 
Boiled & $88 \%$ & $31 \%$ & $25 \%$ \\
Longed & $88 \%$ & $38 \%$ & $6 \%$ \\
Jogged & $94 \%$ & $31 \%$ & $13 \%$ \\
Towed & $94 \%$ & $31 \%$ & $0 \%$ \\
Realized & $94 \%$ & $31 \%$ & $6 \%$ \\
Followed & $94 \%$ & $31 \%$ & $6 \%$ \\
Dragged & $94 \%$ & $38 \%$ & $0 \%$ \\
Grabbed & $100 \%$ & $56 \%$ & $13 \%$ \\
Managed & $100 \%$ & $63 \%$ & $25 \%$ \\
Arranged & $100 \%$ & $69 \%$ & $13 \%$ \\
\hline
\end{tabular}

As can be seen in Table 7, the words with the least number of errors differ from one level of English proficiency to another. For instance, high beginners had fewer error with the words agreed and disagreed, $6 \%$ wrong each. The easiest words for the intermediate proficiency level were clued with $6 \%$ wrong and glued with $0 \%$ wrong. The words with the highest percentages of errors also differed among levels of proficiency. For example, 100\% of the high beginning proficiency level failed to produce correctly the words grabbed, managed, and arranged. The intermediate level had the most difficulty with the word arranged $(69 \%)$. In the case of the high intermediate level, the words with the highest number of errors were managed and boiled with $25 \%$ wrong each respectively. The most common errors were /ad or $\mathrm{Id} /$ instead of / $\mathrm{d} /$ or deletion of the $-e d$ inflection.

In summary, the results of this study showed a developmental trend in the read-aloud production of the past tense $-e d$ inflectional morpheme. However, the effect of proficiency level was not the same for the three realizations of the edaffixal morpheme. As shown in Figure 3, the highest effect of proficiency was observed in regard to the production of the phonological realization $/ \mathrm{d} /$ of the English past morpheme $-e d$, partial Eta squared $=.736$. Lastly, the second most significant effect size was observed in the performance of the / $\mathrm{t} /$ allomorph, Eta squared $=.673$. 


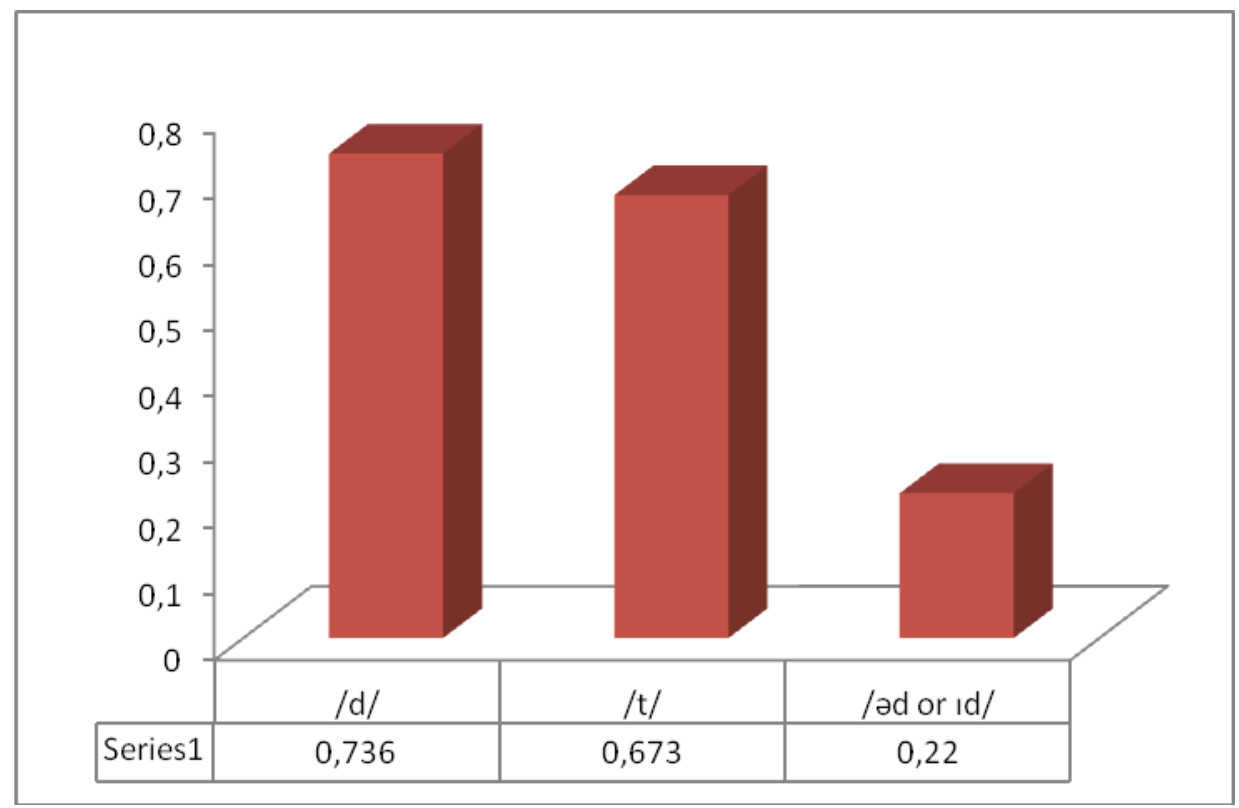

Figure 3. Effect size values for the three ANOVAs from the highest to the lowest

\section{Discussion}

In view of empirical research and theory, the first research question that this study sought to answer was whether the accurate pronunciation of the three allomorphs of the -ed past tense inflection increases with level of English proficiency. The results revealed different trends in view of the relationship between level of proficiency and the production of the three different allomorphs of $-e d$. For example, there was no significant difference among the three levels of English proficiency on the performance of the least marked allomorph, /əd, Id/, of the $-e d$ ending. Moreover, the error rate for all proficiency levels was rather small, with values of $20 \%, 28 \%$, and $23 \%$ for the beginner, intermediate, and high intermediate groups, respectively. This result was expected in view of the Markedness Differential Hypothesis (Eckman, 1977) since the -ed allomorph presents an unmarked syllable in coda position for Spanish learners of English whose first language allows only -VC syllables in final position (Hansen, 2004; Harris, 1983; Nathan, 2008; Shepherd, 2003; Yavas \& Core, 2001).

Interestingly, the beginner group showed the lowest error rate. The slightly better performance of the beginner group of $8 \%$ (20\% vs. $28 \%$ ) or $3 \%$ (20\% vs. $23 \%$ ) over the intermediate and high intermediate groups, respectively, could be related to the Similarity Differential Rate Hypothesis which predicts that beginning L2 learners may outperform higher level L2 learners in the production of linguistic elements which are similar in the L1 and the L2 due to transfer (Major \& Kim, 1996). That is to say, since Spanish phonotactic constraints allow -VC syllables word-finally, beginning EFL Spanish speakers might have transferred this linguistic element as they produced the / əd, Id/ variation of the ed past marker.

With regard to the pronunciation of the more marked phonological versions of the $-e d$ morpheme, $/ \mathrm{t} /$ and $/ \mathrm{d} /$, the findings clearly demonstrated that proficiency level played a significant role. For instance, in the production of $/ \mathrm{t} /$, 
the results revealed a significant pronunciation error rate decrease of $87 \%$ for high beginners, $42 \%$ for intermediate, and $9 \%$ for high intermediate. As for the allomorph /d/, a similar trend was observed wherein the error rate declined from $69 \%$ (high beginners) to $28 \%$ (intermediate) to $8 \%$ (high intermediate).

These results provide evidence in support of the Markedness Differential Hypothesis by Eckman (1977), in that speakers from the three levels of English proficiency faced linguistic problems when producing these two allomorphs. Nevertheless, these findings are best supported by the Similarity Differential Rate Hypothesis (Major \& Kim, 1996) which postulates that MDH should not be examined separately from level of proficiency.

According to the SDRH (Major \& Kim, 1996), marked linguistic elements constitute problems for learners at the lower levels of proficiency, but not for learners at higher levels. In the context of the present study, the more marked allomorphs / t/ and /d/ elicited high percentages of errors in the high beginner group ( $87 \%$ and $69 \%$ ), but as the level of proficiency increased the percentages of errors significantly declined to a minimum of $9 \%$ and $8 \%$ for the high intermediate group.

The second research question aimed to find out which one of the three phonological realizations of the-ed morpheme was the most mispronounced by EFL Spanish learners. The results showed that the level of pronunciation difficulty of the three allomorphs of the -ed morpheme varied from one level of English proficiency to the others. For example, for the high beginner EFL Spanish learners of English the more marked allomorphs / $t /$ and / $d /$ proved to be more difficult to pronounce accurately. In this group, the error rate for $/ \mathrm{t} /$ reached $87 \%$ and for $/ \mathrm{d} / 69 \%$. The easiest allomorph to be pronounced by the beginner group was / $\mathrm{d}$, Id/ with the lowest error rate of $20 \%$. In the intermediate group the most difficult allomorph was shown to be $/ \mathrm{t} /$ with an error rate of $42 \%$, whereas / d/ and / $\mathrm{dd}$, Id/ elicited an error rate of $28 \%$. The high intermediate group showed an opposite trend to the one observed in the beginner group. For them the most errors, although at a low rate of $23 \%$, were observed in relation to /od or Id/ with errors of only $9 \%$ for $/ \mathrm{t} /$ and $8 \%$ for $/ \mathrm{d} /$.

Putting together the error rate of all three groups for each of the three allomorphs produced the following mean error rates in descending order: $49.66 \%$ for $/ \mathrm{t} /, 35 \%$ for $/ \mathrm{d} /$ and $26.66 \%$ for $/ \mathrm{\partial d}$, Id/. So, of the three allomorphs, the most errors were observed in relation to $/ \mathrm{t} /$, the rate reaching almost $50 \%$. The explanation why $/ \mathrm{t} /$ showed the highest mean error can be attributed to the fact that $/ \mathrm{t} /$ seems to be the most marked allomorph of the -ed past tense inflection for Spanish EFL learners. This is because it forms consonant clusters with the preceding voiceless consonants which are disallowed in Spanish, such as [-kt], [pt], [-ft], [-t ft](Dalal \& Loeb, 2005). It should also be noted here, that despite the high mean error rate for this allomorph, the high intermediate group had only $9 \%$ errors. This finding clearly provides evidence in support of the SDRH (Major \& Kim, 1996) which postulates that as the level of proficiency increases, marked linguistic elements cease to cause production problems.

The results also revealed that some words were more difficult than others within each allomorph of the -ed morpheme. Concerning the $/ \mathrm{t} /$ phonological realization, the word laughed was the most difficult for each proficiency level. This word registered $100 \%$ mispronunciation rates by high beginners, $69 \%$ by intermediate, and $19 \%$ by high intermediate. This could be due to an increased 
difficulty of pronouncing the consonant cluster formed by the two voiceless consonants, the fricative $/ \mathrm{f} /$ and the stop $/ \mathrm{t} /$.

Regarding the allomorph /d/, the highest error rates were observed in the pronunciation of the verbs managed, arranged, and grabbed. In these three words, the high beginner group scored $100 \%$ pronunciation error. The intermediate level showed $63 \%$ wrong for the token managed, $69 \%$ for arranged and $56 \%$ for grabbed. Out of the three levels of English proficiency, the high intermediate level presented the lowest error percentages in these three tokens, $25 \%$ when producing the verb managed, $13 \%$ when pronouncing the words arranged and grabbed. The linguistic difficulty of these words for EFL Spanish learners might be explained due to the phonotactic constraints because the combinations such as [-dzd] and [-bd] are non-existent word-finally in Spanish, and this fact might make them hard to be produced (Altenberg, 2005).

On the other hand, the words which elicited the highest level of accurate pronunciation by all three groups of proficiency were agreed, disagreed, glued and clued. This can be explained by the -VC syllable structure of the coda containing the past tense -ed inflection, which is also found in Spanish (Nathan, 2008). So, in the case of the above mentioned words, it can be presumed that there was a positive transfer from participants' L1 to their L2. It can be elucidated from a markedness view point as well because - VC combinations would be less marked in Spanish than words ending in complex consonant clusters (Eckman, 1977; Greenberg, 1978; Helman, 2004).

Lastly, pronunciation difficulties found in this study were of two types, deletion of the

$-e d$ inflection and insertion of $/ \mathrm{\partial} /$ or short /I/. These two types of errors were observed in relation to the three allomorphs $/ \mathrm{t} /, / \mathrm{d} /$, and / $\mathrm{dd}$, Id/. They were most prevalent in the high beginner group and decreased significantly in the high intermediate group. These findings provide further empirical evidence to the observations made in several related studies (e.g. Demuth et al., 2006; Helman, 2004; Lee, 1987; Yavas \& Core, 2001) which have reported that deletion and use of the epenthetic vowels are strategies utilized by beginner EFL Spanish speakers when faced with complex word-final clusters which do not exist in their L1.

\section{Pedagogical Implications}

Mastering the three phonological realizations of the -ed inflectional morpheme, /t/, /d/ and / əd, Id/, should be a target for Spanish speakers acquiring English as a second language. According to Akram (2010), Becker and Kluge (2014), Jin and Liu (2014), and Smith (2011), the more intelligible EFL acquirers are, the more successful their interaction in English becomes. In this sense, empirical data can provide valuable insights to English language teachers.

The results of this study implicate several useful trends. First, they show that of the three allomorphs the most difficult is $/ t /$, followed by $/ d /$ and the easiest one is / əd or $\mathrm{Id} /$. These findings show that those linguistics features dissimilar between English and Spanish deserve explicit instruction, for instance, 
complex word-final clusters and non-coronals. In terms of classroom practices, teachers should introduce aspects of English and Spanish phonotactic constrains to their EFL Spanish students when teaching the regular past tense in English. Teachers should, first, help their students notice the differences in pronouncing the three variants and then provide adequate and continuous practice and corrective feedback.

The findings show as well that the accurate production of the -ed morpheme improves with the level of English proficiency. It is implied, therefore, that if EFL Spanish learners are exposed to extensive oral English data, containing the usage of the three allomorphs of the English inflectional morpheme - ed, they may overcome pronunciation errors such as deletion and epenthetic vowel insertion in a more optimal way.

Finally, the findings also suggest that the curriculum devoted to the teaching of English as a foreign language should include instructional methods that focus on explicit pronunciation besides focusing on communication skills.

\section{Conclusion}

This study concluded that markedness alone could not be viewed as the only theory that could explain the difficulties in the acquisition of more marked linguistic components between the Spanish (L1) and English (L2) because this study showed a developmental trend. That is, the MDH proved to be strong when EFL Spanish speakers are just at the onset of the acquisition of the more marked allomorphs of the $-e d$ morpheme, /t/ and /d/. However, as the level of English proficiency becomes more and more developed, the accurate pronunciation of the -ed ending becomes easier and easier for these types of learners, and markedness becomes less important. As a result, the Similarity Differential Rate Hypothesis proved to be more effective in providing better explanations than the Markedness Differential Hypothesis concerning the acquisition of similar and dissimilar linguistic characteristics such as the phonological acquisition of the - ed morpheme by EFL Spanish speakers.

\section{Acknowledgements}

Firstly, I would like to thank from the bottom of my heart my wife and son for their priceless support, encouragement, and patience while I was conducting this study. It was thanks to them that I felt motivated to carry it out. Secondly, I would like to thank the research participants who voluntarily participated in my study. Lastly, I am grateful to Dr. Krassimira Charkova, Dr. Karen Baertsch, and Dr. James Berry, all faculty in the Linguistics Department at Southern Illinois University. They were a very important source of encouragement, motivation, guidance and support during the whole process of this study. Her genuine enthusiasm kept me focused and helped me to successfully get this study done. 


\section{References:}

Abushihab, I. (2010). Phonological contrastive analysis of Arabic, Turkish and English. Journal of Language 83 Literature (20780303), (4), 16-24.

Akram, M. (2010). Teaching pronunciation: Views and approaches of secondary teachers in Punjab. Kashmir Journal of Language Research, 13(2), 59-69.

Altenberg, E. P. (2005). The judgment, perception, and production of consonant clusters in a second language. International Review of Applied Linguistics in Language Teaching, 43, 53-80. doi:10.1515/iral.2005.43.1.53

Androutsopoulou, A., Español-Echevarría, M., \& Prévost, P. (2010). The syntax/morphology interface in Spanish L2 acquisition: Focus on quantified DPs. Canadian Journal of Linguistics, 55(2), 149-180.

Baker, D. K. (2011). Effect of Reading Comprehension on Passage Fluency in Spanish and English for Second-Grade English Learners. School Psychology Review, 40(3), 331.

Becker, M. R., \& Kluge, D. C. (2014). Intelligibility of English as a lingua franca (ELF): Perception by speakers of Brazilian Portuguese. In Proceedings of the International Symposium on the Acquisition of Second Language Speech Concordia Working Papers in Applied Linguistics, 5, 50-57.

Birdsong, D. (1999). Introduction: Whys and why nots of the critical period hypothesis for second language acquisition. In Second Language Acquisition and the Critical Period Hypothesis, David Birdsong (ed.), 1-22. Mahwah, NJ: Lawrence Erlbaum Associates.

Bowden, H., Gelfand, M. P., Sanz, C., \& Ullman, M. T. (2010). Verbal inflectional morphology in L1 and L2 Spanish: A frequency effects study examining storage versus composition. Language Learning, 60(1), 44-87. doi:10.1111/j.1467-9922.2009.00551.x

Carlisle, R. S. (1998). The acquisition of onsets in a markedness relationship: A longitudinal study. Studies in Second Language Acquisition, 20, 245-260. doi:10.1017/S027226319800206X

Carlisle, J. (2000). Awareness of the structure and meaning of morphologically complex words: Impact on reading. Reading and Writing, 12(3-4), 169-190.

Commissaire, E., Duncan, L. G., \& Casalis, S. (2011). Cross-language transfer of orthographic processing skills: A study of French children who learn English at school. Journal of Research in Reading, 34(1), 59-76. doi:10.1111/j.1467-9817.2010.01473.x

Dalal, R., \& Loeb, D. (2005). Imitative production of regular past tense -ed by English-speaking children with specific language impairment. International Journal of Language 83 Communication Disorders, 40(1), 67-82. doi: 10.1080/13682820410001734163

Davidson, L. (2011). Phonetic and phonological factors in the second language production of phonemes and phonotactics. Linguistics \& Language Compass, 5, 126-139. doi:10.1111/j.1749818X.2010.00266.x

Demuth, K., Culbertson, J., \& Alter, J. (2006). Word-minimality, epenthesis and coda licensing in the early acquisition of English. Language \& Speech, 49(2), 137-174.

Dörnyei, Z. (2009). Individual Differences: Interplay of Learner Characteristics and Learning Environment. Language Learning, 59230-248.

Eckman, F. R. (1977). Markedness and the contrastive analysis hypothesis. Language Learning 27, 315-330.

Eckman, F. R. (2008). Typological markedness and second language phonology. In Zampini and Hansen (Eds.), Phonology and second language acquisition (pp. 2-31). Milwaukee: Cambridge University Press.

Eckman, F. R., Elreyes, A., \& Iverson, G. K. (2003). Some principles of second language phonology. Second Language Research, 19(3), 169-208. doi: 10.1191/0267658303sr2190a

Ghapanchi, Z., Khajavy, G., \& Asadpour, S. (2011). L2 Motivation and Personality as Predictors of the Second Language Proficiency: Role of the Big Five Traits and L2 Motivational Self System. Canadian Social Science, 7(6), 148-155.

Gildersleeve-Neumann, C. E., Kester, E. S., Davis, B. L., \& Peña, E. D. (2008). English speech sound development in preschool-aged children from bilingual English-Spanish environments. Language, Speech $\&$ Hearing Services In Schools, 39(3), 314-328. doi:10.1044/0161-1461(2008/030)

Goldstein, B. (2001). Transcription of Spanish and Spanish-influenced English. Communication Disorders Quarterly, 23(1), 54-60.

Greenberg, J. H. (1978). Some generalizations concerning initial and final consonant clusters. In J. H. Greenberg, C. A. Ferguson, E. A. Moravcsik (Eds.), Universals of Human Language (p. II:243). Stanford: Stanford UP. 
Hansen, J. G. (2004). Developmental sequences in the acquisition of English L2 syllable codas: A preliminary study. Studies in Second Language Acquisition, 26(1), 85-124. doi: $10+10170$ S0272263104261046

Harris, J. W. (1983). Syllable structure and stress in Spanish: A Nonlinear Analysis. Cambridge, MIT Press.

Helman, L. A. (2004). Building on the sound system of Spanish: Insights from the alphabetic spellings of English-language learners. Reading Teacher, 57(5), 452-460.

Hyltenstam, K. (1987). Markedness, language universals, language typology and second language acquisition. In Carol Pfaff (ed.) First and second language acquisition processes (55-78). Newbury House: Cambridge (Mass.).

Hu, C. (2010). Phonological bases for L2 morphological learning. Journal of Psycholinguistic Research, 39(4), 305-322.

Jenkins, J. (2004). Research in teaching pronunciation and intonation. Annual Review of Applied Linguistics, 24, 109-125. doi: 10.1017/S0267190504000054

Larsen-Freeman, D. (2000). Techniques and principles in language teaching. Oxford: Oxford University Press.

Lee, J. F. (1987). A developmental hierarchy of syllabic difficulty. Hispania, 70(2), 357-362.

Lleó, C. (2003). Prosodic licensing of codas in the acquisition of Spanish. Probus: International Journal of Latin and Romance Linguistics, 15(2), 257-281. doi:10.1515/prbs.2003.010

Long, M., H. (1990). Maturational constraints on language development. Studies in Second Language Acquisition 12: 251-285

Major, R. C., \& Kim, E. (1996). The similarity differential rate hypothesis. Language Learning, 46(3), 151-183.

Nathan, G. S. (2008). Phonology: A cognitive grammar introduction. Amsterdam \& Philadelphia: John Benjamins.

Nation, I.S.P., \& Newton, J. (2009). Teaching ESL/EFL listening and speaking. New York and London: Routledge Taylor and Francis Group.

Jin, S. H., \& Liu, C. (2014). Intelligibility of American English vowels and consonants spoken by international students in the United States. Journal of Speech, Language, and Hearing Research, 57(2), 583-596.

Johnson, J. S., \& Newport, E. L. (1989). Critical period effects in second language learning: The influence of maturational state on the acquisition of English as a second language. Cognitive Psychology, 21, 60-99.

Ożańska-Ponikwia, K., \& Dewaele, J. (2012). Personality and L2 use: The advantage of being open-minded and self-confident in an immigration context. EUROSLA Yearbook, 12(1), 112-134.

Ramirez, G., Chen, X., Geva, E., \& Kiefer, H. (2010). Morphological awareness in Spanishspeaking English language learners: Within and cross-language effects on word reading. Reading and Writing, 23(3/4), 337-358.

Rauber, A., \& Baptista, B. (2004). The production of English initial /s/ clusters by Portuguese and Spanish EFL speakers. Revista De Estudos Da Linguagem, 12(2), 459-473.

Reichle, R. V. (2010). Judgments of information structure in L2 French: Nativelike performance and the Critical Period Hypothesis. IRAL: International Review of Applied Linguistics in Language Teaching, 48(1), 53-85. doi:10.1515/iral.2010.003

Richards, J. C. (2008). Teaching listening and speaking: From theory to practice. New York: Cambridge University Press.

Salaberry, M. R. (2000). The acquisition of English past tense in an instructional setting. System, 28(1), 135-152.

Schwartz, B., D. (1993). On explicit and negative data effecting and affecting competence and linguistic behavior. Studies in Second Language Acquisition, 15, 147-163. doi:10.1017/S0272263100011931.

Sebastián-Gallés, N., \& Bosch, L. (2002). Building phonotactic knowledge in bilinguals: Role of early exposure. Journal of Experimental Psychology: Human Perception and Performance, 28, 974989. doi:10.1037/0096-1523.28.4.974

Shepherd, M. A. (2003). Constraint interactions in Spanish phonotactics: An optimality theory analysis of syllable level phenomena in the Spanish language. (Master's thesis). California State University, Northridge.

Smith, J. (2011). Teaching pronunciation with multiple models. New Zealand Studies in Applied Linguistics, 17(2), 107-115.

Storkel, H. L., Maekawa, J., \& Hoover, J. R. (2010). Differentiating the effects of phonotactic probability and neighborhood density on vocabulary comprehension and production: A comparison of 
preschool children with versus without phonological delays. Journal of Speech, Language 83 Hearing Research, 53(4), 933-949. doi:10.1044/1092-4388(2009/09-0075)

Wang, M., Park, Y., \& Lee, K. (2006). Korean-English biliteracy acquisition: Cross-language phonological and orthographic transfer. Journal of Educational Psychology, 98(1), 148-158. doi:10.1037/0022-0663.98.1.148

Wesely, P. M. (2012). Learner attitudes, perceptions, and beliefs in language learning. Foreign Language Annals, 45(S1), s98-s117.

Yassin, S. (2008). Identifying Problems and Implementing Solutions: The Production of Consonant Sounds in Spoken English among EFL/ESL Learners. International Journal of the Humanities, 6(5), 5-14.

Yavas, M. S., \& Core, C. W. (2001). Phonemic awareness of coda consonants and sonority in bilingual children. Clinical Linguistics \&3 Phonetics, 15, 35-39. doi:10.1080/026992001461271 